\title{
A Self-Directed in Learning among Undergraduate Nursing Students' in School of Nursing and Midwifery, TUMS, Tehran, Iran
}

\author{
Addis Adera Gebru ${ }^{1,}$,, Shahrazad Ghiyasvandian ${ }^{1}$, Noorodin Mohammodi ${ }^{2}$, Markos Kidane ${ }^{3}$ \\ ${ }^{1}$ Department of Medical Surgical Nursing, School of Nursing and Midwifery, Tehran University of Medical Sciences, Tehran, Iran \\ ${ }^{2}$ Department of Critical Care Unit, School of Nursing and Midwifery, Tehran University of Medical Sciences, Tehran, Iran \\ ${ }^{3}$ Department of Economics, Faculty of Business and Economics, Unity University, Addis Ababa, Ethiopia \\ Email address: \\ addisaderagebru@gmail.com (A. A. Gebru)
}

\section{To cite this article:}

Addis Adera Gebru, Shahrazad Ghiyasvandian, Noorodin Mohammodi, Markos Kidane. A Self-Directed in Learning among Undergraduate Nursing Students' in School of Nursing and Midwifery, TUMS, Tehran, Iran. Education Journal. Vol. 4, No. 4, 2015, pp. 158-165.

doi: $10.11648 /$ j.edu.20150404.13

\begin{abstract}
Back ground: Teaching-learning contributes to the development of professional values, attitudes and behavior through a partnership of accountability between teacher and learner. Objective: To determine self-directed in learning among undergraduate nursing students' in School of Nursing and Midwifery, Tehran University of Medical Sciences, Tehran, Iran. Method: A cross sectional descriptive study was conducted from Jan, 2013 up to March, 2014 at school of nursing and midwifery of Tehran University of Medical Sciences, Tehran, Iran. A total of 232 undergraduate nursing students' were involved in the study. Data was collected from selected students through an anonymous self-administrated questionnaire. The questionnaire was divided into two sections including (a) demographic profile and (b) Fisher's Self-Directed in Learning Readiness questionnaire. Data analysis was carried out by using the latest version of the statistical software package SPSS (Version-21). Descriptive and analytical statistical test were used to analyze the data. Results: A total of 232 participated in study of determination of self-directed in learning among undergraduate nursing students' in School of Nursing and Midwifery, Tehran University of Medical Sciences, Tehran, Iran. One hundred forty-three participants were female (61.6\%), and 89(38.4\%) of participants were male. The majority $(60.8 \%)$ of participants were in the age group of $20-25$ years.. The majority $(90.52 \%)$ of subjects self-directed in learning readiness were in the level of Self-Control (Score $>150)$. The mean score of selfmanagement, desired for learning, Self-control and the overall SDLR were similar in a student's $(31.84 \pm 6.174 ; 31.83 \pm 6.177)$. Conclusion: Not all students are self-directed, and this study suggests that mature students are more self-directed than that entering nurse education direct from high school.
\end{abstract}

Keywords: Self-directed Learning, Nursing Students, Iran, Undergraduate Degree

\section{Introduction}

Self-directed learning is materialized when learners direct, and regulate their own learning process and experience selfactualization through deciding on the materials, methods, and goals of learning. Manifestly, learning does not necessarily occur in formal, educational settings because learners can learn all by themselves in informal settings. Taking a great deal of initiative in their own learning, learners can choose learning strategies independently of their teachers. To have a developed self, it is highly recommended that learners manage their own learning process through engagement in Self-directed learning (1).As important as understanding the concept of SDL is a method of instruction used increasingly in adult education with in tertiary institution(2,3,4).SDL defines as 'a process in which individuals take the initiative, with or without the help of others, in diagnosing their learning needs, formulating learning goals, identifying human and material resources for learning, choosing and implementing appropriate learning strategies and evaluating learning outcomes (5). There are many studies that attempted to identify the patterns which existed among the students LS and their socio-demographic characteristics (Age, Achievement, Ethnicity, Gender and Nationality)(6).

Dynan and his colleagues (2008) found that courses which were designed to enhance student readiness for self-directed 
in learning could in fact do so. Their students, like many others, entered courses unprepared for engagement in selfdirected learning (SDL). However, when students modeled professor inquiry in a structured learning environment, their readiness for self-directed learning improved. The finding was indicated that "skill of self-direction in learning is one that is essential for students and workers to remain lifelong learners" and "it is, at least in part, up to professors to encourage and develop this skill in their students so that they will be equipped for educational opportunities and challenges beyond their formal education"(7).In few literatures, SDL is characterized by a proactive approach to learning where individuals take responsibility for identifying necessary learning resources and implementing strategies appropriate for their goals(4,7). Self-directed learning is a method of instruction used increasingly in adult education and it is needed for nursing students, to be prepared for present challenges in the healthcare system(8). Self-directed learning includes the dimensions of self-management, self-monitoring and motivation. Self-management describes a learner setting goals and managing available resources and support. Selfmonitoring encompasses cognitive process required to construct individual meaning of new concepts $(9,10,11,12)$. The purpose of this study was to determine the self-Directed in Learning among undergraduate nursing students.

\section{Methods and Materials}

\subsection{Study Area and Period}

This study was conducted in school of Nursing and Midwifery, Tehran University of Medical Sciences, Tehran, Iran. The school of nursing and Midwifery is proud of its 70+ year history of education and pioneering position in research. Established in 1936, this school has always been one of the strongest schools in nationally and regionally. With more than 1471 undergraduate and graduate nursing and midwifery students, 83 faculty members and presenting top alumini at all levels, the influence of this school in Virtually all National and regional nursing and Midwifery events is undeniable. The study was conducted in 232 randomly selected under graduated Nursing students from Jan, 2013 up to March, 2014.

\subsection{Study Design}

A cross-sectional descriptive study design was used for documenting the self-directed in learning among undergraduate nursing students' in TUMS, Tehran, Iran.

\subsection{Study Population}

Sampled undergraduate nursing students were attending at School of nursing and Midwifery, Tehran University of Medical Sciences, Tehran, Iran prior to the study. The study population consisted of all undergraduate nursing students who attended at the school of nursing and midwifery and they can fulfill the criteria for inclusion was enrolled in the study.

\subsection{Sampling Size}

The sample size was calculated using employing stratified population in order to determine statistical formula. When $\mathrm{n}=$ Sample size with finite population correction, $\mathrm{Z} 1-\alpha / 2=$ the standard normal variables at (1- $\alpha) \%$ confidence level and $\alpha=5 \%$ with $95 \%$ confidence interval level $=1.96, S=$ Standard Deviation, and $\mathrm{d}=\mathrm{is}$ margin of the sample error to be tolerated/precision/length (in proportion of one) of maximum error $=0.8)$. (13). the study was included at least 221 students, then the total students who enrolled at study area is 743 nursing students. The required sample is obtained and with $5 \%$ non-response rate of total were calculated 232 were obtained.

\subsection{Sampling Techniques}

A Quota Stratified Sampling Techniques (QSST) was employed. In School of Nursing and Midwifery, Tehran University Of Medical Science, there are more than 1471 undergraduate and graduate nursing and midwifery students, 83 faculty members and presenting top alumini at all levels, the influence of this school in Virtually all National and regional nursing and Midwifery events is undeniable. All undergraduate nursing students from the total number of students about 232 were selected. Total undergraduate nursing students in the school from 2009-2013 were about 743 persons. Regarding the sampling technique, study group from the source of population were choices for each academic year of the nursing study (Year 1-4): Year1 (67), Year 2(69), year 3 (65), and year4 (31).

\subsection{Instruments and Measurements}

Data was collected from students through an anonymous self-administrated questionnaire. The questionnaire was divided into two sections including (a) demographic profile: Age, Sex, Marital status, permanent residence, living area ,department, grade level, academic achievement, average hours of independent study, Average hours for social activities, and students study planning. It was consists all these variables, an interviewer-administrated questionnaire was also used to obtain the necessary information from the respondents. The self-Directed learning tool is a 40 -items five point scale listing a number of self-Directed were required to rate themselves in terms of the degree to which they believed the statement in the scale described their approach to learning .It is desirable while mentioning here that researcher was compared to Fisher as follows' completely "Disagree", for those who were not self-Directed and the range of scores is less than 40.A measurement of individual sense of ranging from "Completely agree " to "Strongly disagree". The instrument is a 40 - items five point linker scale. Scores was assigned as $<48.75$ " strongly Disagree" forself-management, $>48.75$ "Strongly Disagree" for Self-management, $>48.75$ "Strongly agree" for Selfmanagement, $<45$ "Strongly Disagree" for Self -Desired in Learning, > 45 "Strongly agree" for self-desired in learning, $<56.25$ "Strongly Disagree" for Self-control, > 
56.25 Strongly agree" for Self-control and $<150$ "Strongly Disagree" for Total SD in Learning, > 150 "Strongly agree" for Total SD in Learning (Safavi et al., 2010.).The questionnaire was administered by the data collectors.

\subsection{Data Collection Procedure}

The questionnaire was developed and pretested among small number of non-sample group nursing students in the school of nursing students in the school of nursing and Midwifery, TUMS, Tehran, Iran. Before pretesting, the research team discussed the instrument to make sure that all involved in data collection understood and were acquainted with the instrument. The instrument was revised based on the issues identified by the team. The improved version of the instruments was used for pretesting exercise. The investigator also was carried out pilot study to ensure content and face validity. The data of the questionnaire from the pilot group was processed for determining an internal consistency reliability for coefficient, The alpha Cronbach's value of 0.98 indicated a high reliable of the questionnaire to determine the relationship between self-directed in learning and sociodemographic characteristics among undergraduate nursing students academic achievement. Both pretesting and actual data collection were conducted in local language commonly spoken in the study area (Persian language-Farsi).One Female trained research assistant who is an instructor at School of Nursing and Midwifery, TUMS, Tehran, Iran, was recruited and assisted the researchers in collecting data for the study .All ethical considerations were applied in this study. The time which allowed filling all questionnaires for one participant was 30 minutes but they could take more time.

\subsection{Data Processing and Analysis}

The completed of the questionnaires were serially numbered for control and recall purposes. Data collected was checked for completeness and accuracy on a daily basis. They quantitative data collected was collated and screened for completeness; Socio-demographic characteristics and learning style section were scored and entered into computer. The statistical package for social sciences (SPSS) version 21 was used for the analysis of data. Descriptive statistics, chisquare and T-test were used. Frequencies were generated and a variable was cross-tabulated. The level of significance for the study was considered $\mathrm{P}<0.05$.

\subsection{Data Quality Control}

To ensure the quality of data, first the questionnaire was pretested. The pretested was conducted in 5\% of the participants at randomly selected undergraduate nursing students in School of Nursing and Midwifery, Tehran University of Medical Sciences, Tehran Iran. The training was given for the data collectors and supervisor before the actual data collection. Every day after data collection, questionnaires were reviewed and checked for completeness, accuracy and clarity by the supervisors and principal investigator.

\subsection{Ethical Consideration}

Approval for the study was sought from the school of nursing and midwifery academic Head and administration body for access to the study area, the medical research Council of Tehran, Iran and the Joint research Ethics committee, Ethical Boards for the protection of human subjects in the study. Verbal information was provided to the respondents to make informed choices on whether to participate in the study or not. No any incentives were provided to the respondents as a way of motivating them to participate in the study. All the participants agreed to response in the study and signed a consent form.

\subsection{Limitation of the Study}

The emotional condition of responders can affect their answer to the study questionnaires; the researcher could not control that situation.

\section{Results}

Table 1, shows that the majority of subjects (90.52\%) SDLR were in the level of Self - Control (Score >150).

Table 1. Distribution of SDL in students.

\begin{tabular}{lll}
\hline Self-Directed In Learning & Frequency (n) & Percentage (\%) \\
\hline Self-Management & 7 & 3.02 \\
Self-Desired in learning & 15 & 6.46 \\
Self-Control & 210 & 90.52 \\
Total & 232 & 100 \\
\hline
\end{tabular}

This table reveals that the majority of subjects $(57.9 \%)$ were female who have higher level of SDLR than male.However,the proportion of high SDLR did not show any significant variation with all sociodemographics of the students.

Table 2. students'Self-directed learning according to some of socio-demographics characteristics

\begin{tabular}{|c|c|c|c|c|c|c|c|c|}
\hline \multirow{3}{*}{ Variables } & \multirow{3}{*}{ Classification } & \multicolumn{7}{|c|}{ Self-directed learning } \\
\hline & & \multicolumn{2}{|c|}{$<150$} & \multicolumn{2}{|l|}{$>150$} & \multicolumn{2}{|c|}{ Total } & \multirow{2}{*}{ Result } \\
\hline & & $\mathbf{n}$ & $\%$ & $\mathbf{n}$ & $\%$ & $\mathbf{n}$ & $\%$ & \\
\hline \multirow{3}{*}{ Sex } & Female & 75 & 64.7 & 66 & 57.9 & 141 & 61.3 & $\mathrm{x}^{2}=1.108^{*}$ \\
\hline & Male & 41 & 35.3 & 48 & 42.1 & 89 & 38.7 & $\mathrm{df}=1$ \\
\hline & Total & 116 & 100 & 114 & 100 & 230 & 100 & $\mathrm{P}=0.344$ \\
\hline \multirow{3}{*}{ Marital Status } & Single & 100 & 86.2 & 103 & 90.4 & 203 & 88.3 & $\mathrm{x}^{2}=0.953^{*}$ \\
\hline & Married & 16 & 13.8 & 11 & 9.6 & 27 & 11.7 & $\mathrm{df}=5$ \\
\hline & Total & 116 & 100 & 114 & 100 & 230 & 100 & $\mathrm{P}=0414$ \\
\hline Self-study planning & Regularly & 38 & 32.8 & 38 & 33.3 & 76 & 33 & $\mathrm{x}^{2}=0.011^{*}$ \\
\hline
\end{tabular}




\begin{tabular}{|c|c|c|c|c|c|c|c|c|}
\hline \multirow{3}{*}{ Variables } & \multirow{3}{*}{ Classification } & \multicolumn{7}{|c|}{ Self-directed learning } \\
\hline & & \multicolumn{2}{|c|}{$<150$} & \multicolumn{2}{|l|}{$>150$} & \multicolumn{2}{|c|}{ Total } & \multirow{2}{*}{ Result } \\
\hline & & $\mathbf{n}$ & $\%$ & $\mathbf{n}$ & $\%$ & $\mathbf{n}$ & $\%$ & \\
\hline \multirow{8}{*}{ Living place } & Exam weeks & 51 & 44 & 50 & 43.9 & 101 & 43.9 & \multirow{3}{*}{$\mathrm{P}=1.000$} \\
\hline & Before the day of exam & 27 & 23.3 & 26 & 22.8 & 53 & 23 & \\
\hline & Total & 116 & 100 & 114 & 100 & 230 & 100 & \\
\hline & Living in TUMS Dormitory & 33 & 28.4 & 44 & 38.6 & 77 & 33.5 & \multirow{5}{*}{$\begin{array}{l}\text { Fisher's exact } \\
\text { test }=2.929 \\
d f=1 \\
\mathrm{P}=0.434\end{array}$} \\
\hline & Home & 15 & 12.9 & 13 & 11.4 & 28 & 12.2 & \\
\hline & Family Home & 66 & 56.9 & 56 & 49.1 & 122 & 53.0 & \\
\hline & Rental & 2 & 1.7 & 1 & 0.9 & 3 & 1.3 & \\
\hline & Total & 116 & 100 & 114 & 100 & 230 & 100 & \\
\hline \multirow{5}{*}{$\begin{array}{l}\text { Average hours of } \\
\text { independent study }\end{array}$} & $0-2$ & 80 & 69.0 & 73 & 64.0 & 153 & 66.5 & \multirow{5}{*}{$\begin{array}{l}\text { Fisher's exact } \\
\text { test }=1.746 \\
\mathrm{df}=1 \\
\mathrm{P}=0.709\end{array}$} \\
\hline & $2.1-4$ & 29 & 25 & 34 & 29.8 & 63 & 27.4 & \\
\hline & $4-6$ & 7 & 6 & 6 & 5.3 & 13 & 5.7 & \\
\hline & $6-8$ & 0 & 0.0 & 1 & 0.9 & 1 & 0.4 & \\
\hline & Total & 116 & 100 & 114 & 100 & 230 & 100 & \\
\hline \multirow{7}{*}{$\begin{array}{l}\text { Average hours for } \\
\text { social activities }\end{array}$} & $0-2$ & 34 & 29.3 & 23 & 20.2 & 57 & 24.8 & \multirow{7}{*}{$\begin{array}{l}x^{2}=4.786^{*} \\
d f=5 \\
P=0.449\end{array}$} \\
\hline & $2.1-4$ & 29 & 25 & 25 & 30.4 & 64 & 27.8 & \\
\hline & $4-6$ & 33 & 28.4 & 28 & 24.6 & 61 & 26.5 & \\
\hline & $6-8$ & 7 & 6.0 & 12 & 10.5 & 19 & 8.3 & \\
\hline & $8-10$ & 5 & 4.3 & 7 & 6.1 & 12 & 5.2 & \\
\hline & $10+$ & 8 & 6.9 & 9 & 7.9 & 17 & 7.4 & \\
\hline & Total & 116 & 100 & 114 & 100 & 230 & 100 & \\
\hline \multirow{5}{*}{$\begin{array}{l}\text { Academic } \\
\text { Year/level of study }\end{array}$} & First-year & 34 & 29.3 & 30 & 26.3 & 64 & 27.8 & \multirow{5}{*}{$\begin{array}{l}\text { Pearson } \\
\left(X^{2}\right)=5.018 \\
d f=3 \\
P=0.171\end{array}$} \\
\hline & Second Year & 41 & 35.3 & 31 & 27.2 & 72 & 31.3 & \\
\hline & Third -year & 31 & 26.7 & 33 & 28.9 & 64 & 27.8 & \\
\hline & Fourth-Year & 10 & 8.6 & 20 & 17.5 & 30 & 13 & \\
\hline & Total & 116 & 100 & 114 & 100 & 230 & 100 & \\
\hline
\end{tabular}

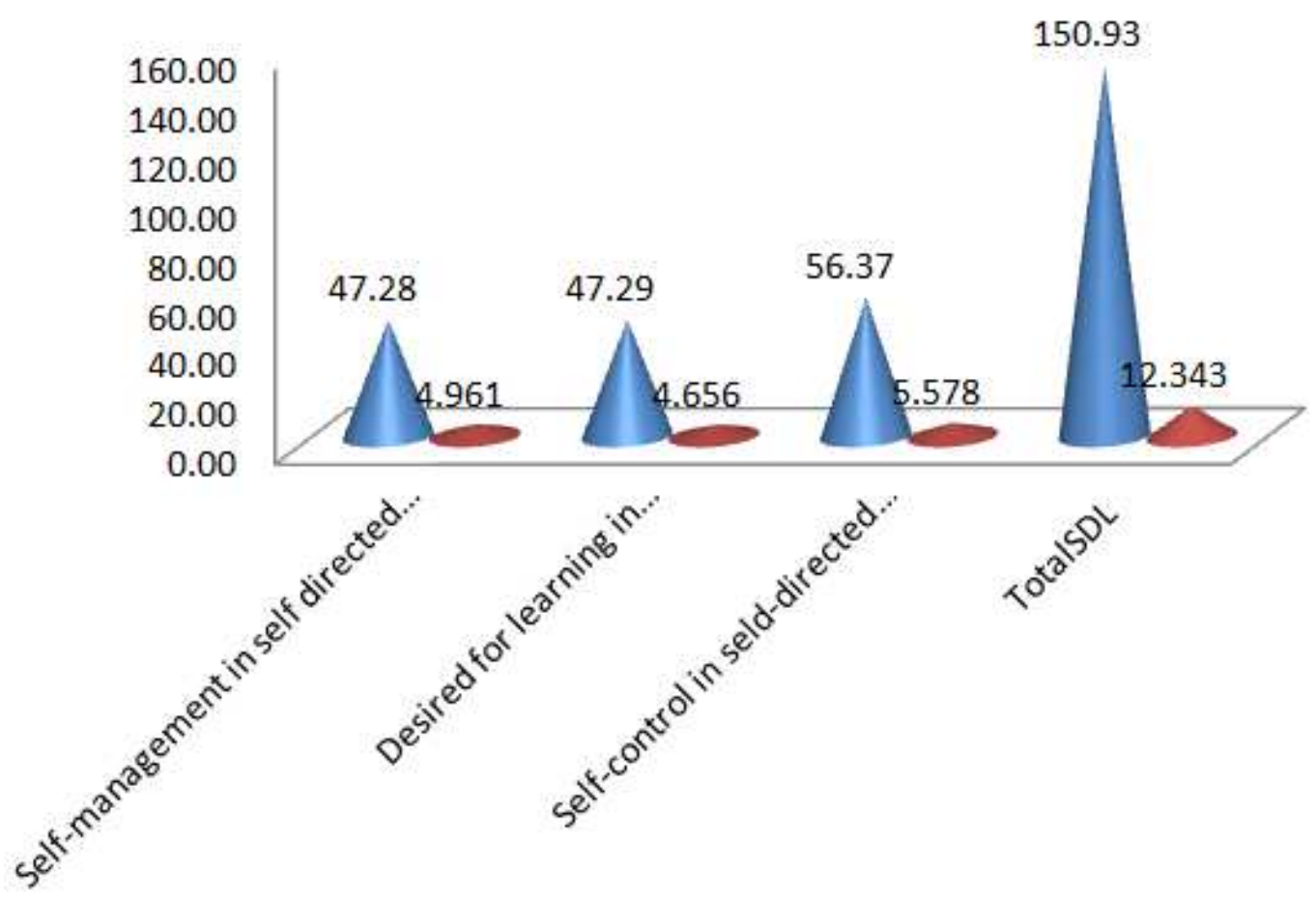

Normal Distribution Location Normal Distribution Scale

Figure 1. Normal distribution location and scale of self-directed in learning among the participants categorized according to classification of self-directed in learning, Tehran University of Medical Sciences, Tehran, Iran.

The normal distribution location of self- control in self directed in learning (56.37:5.578) were higher than normal distribution location and scale of desired for learning in selfdirected in learning (47.29: 4.656) (Fig.1).
The finding in figure. 2, reveals that the majority of subjects SDLR by Observed and Expected cumulative prob of self-directed in learning classification among the participants categorized according to classification of self- 
directed in learning were in the level of Self - Control

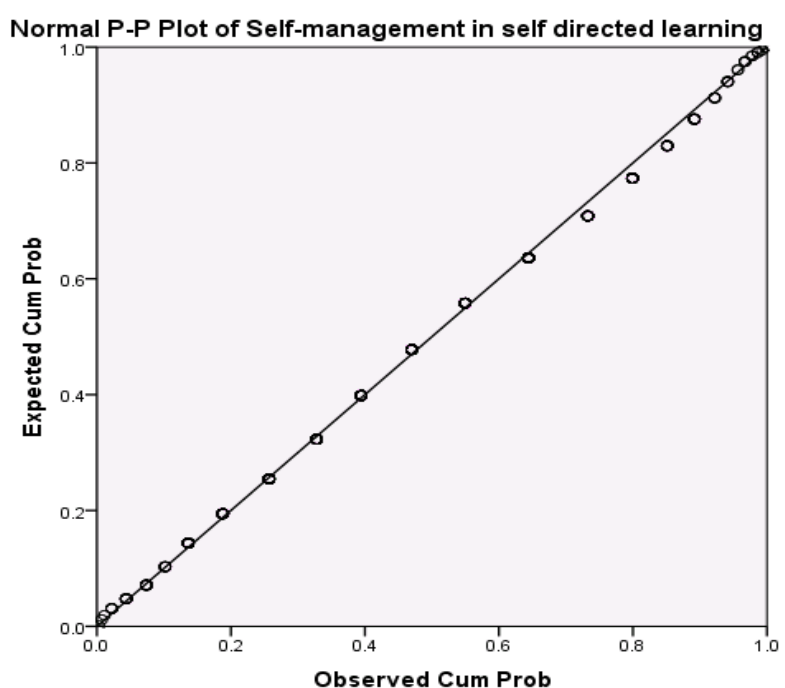

Normal P-P Plot of Desired for learning in Selfdirected learning
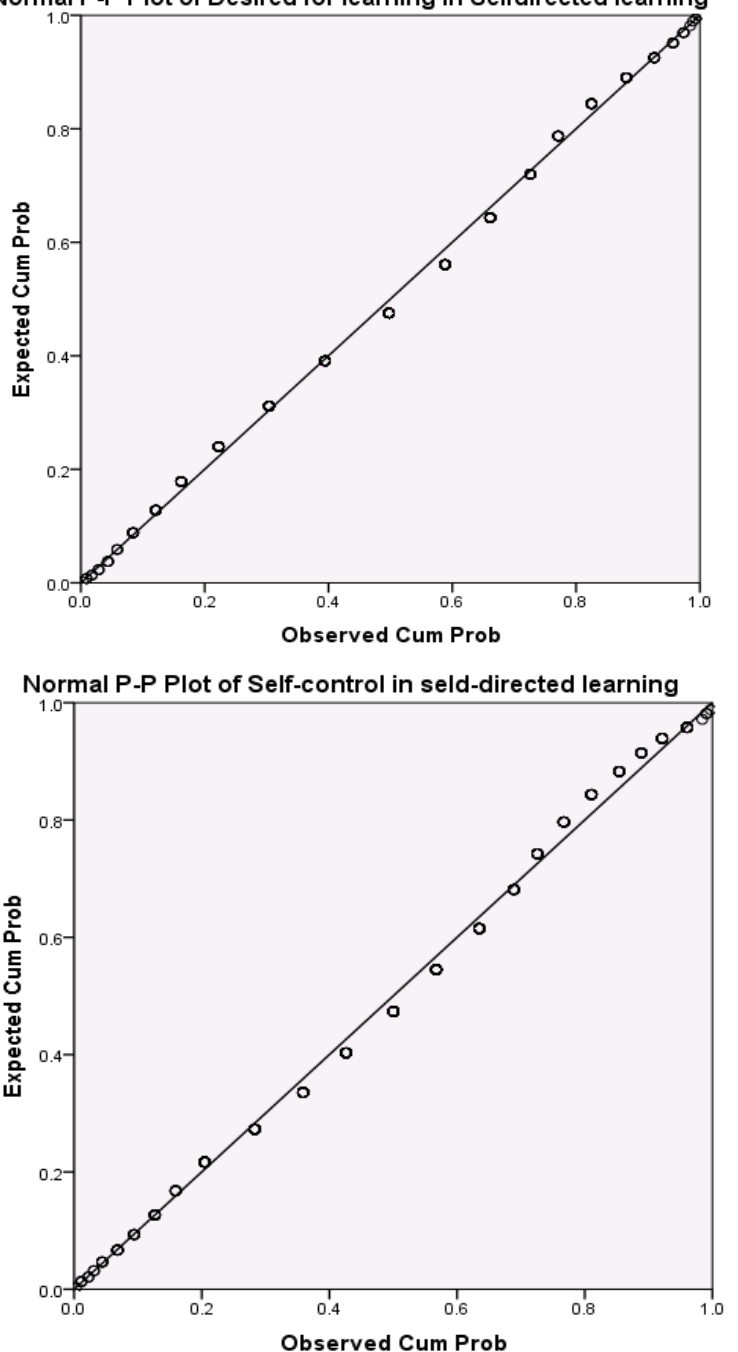

(Score $>150)$

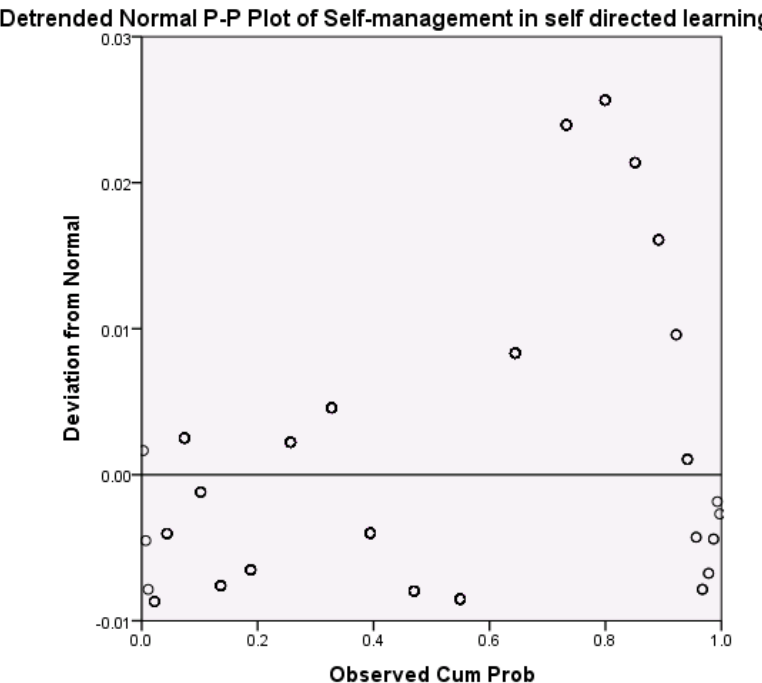

Detrended Normal P.P Plot of Desired for learning in Selfdirected learning

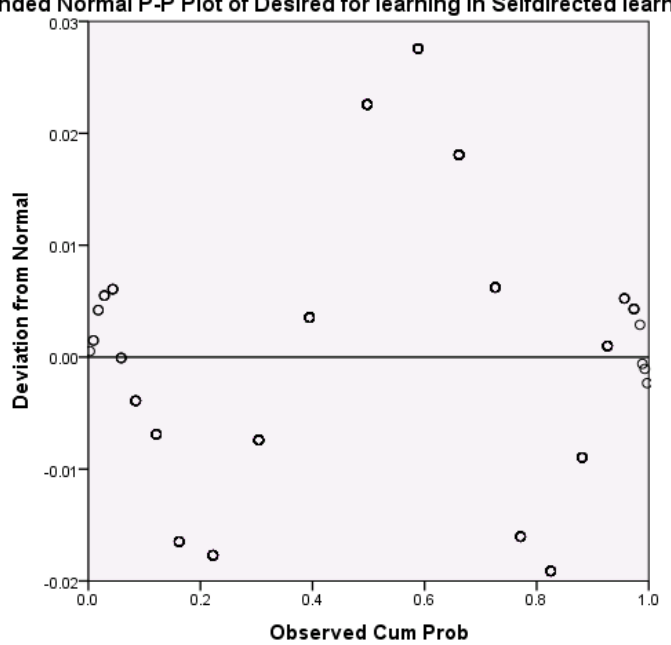

Detrended Normal P-P Plot of Self-control in seld-directed learning

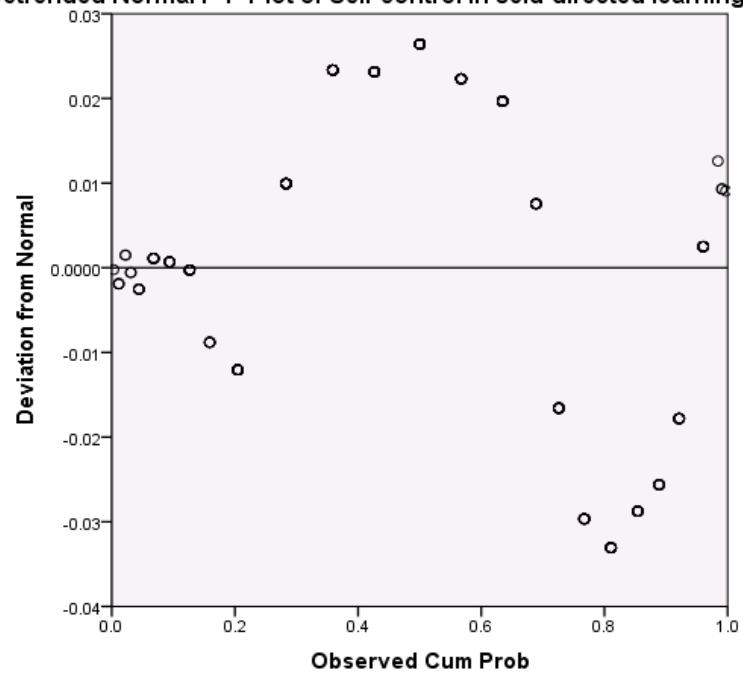



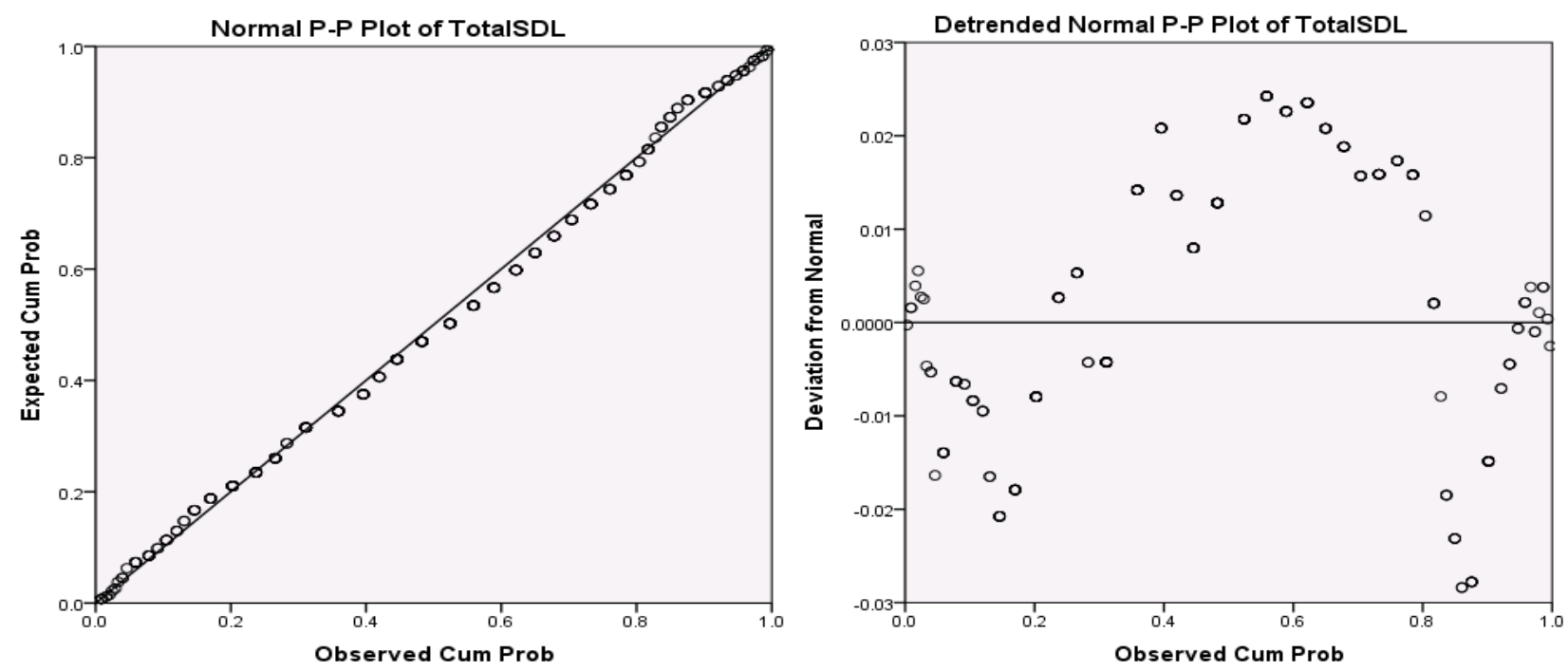

Figure 2. Observed and Expected cumulative prob of self-directed in learning classification among the participants categorized according to classification of self-directed in learning, Tehran University of Medical Sciences, Tehran, Iran.

The majority of the students $135(59.1 \%)$ were selfmanagement category of self-directed in learning .Most of desired for learning, 124(53.4\%) were self-control of self$151(65.1 \%)$ of undergraduate nursing students had used directed in learning (Figure.3)

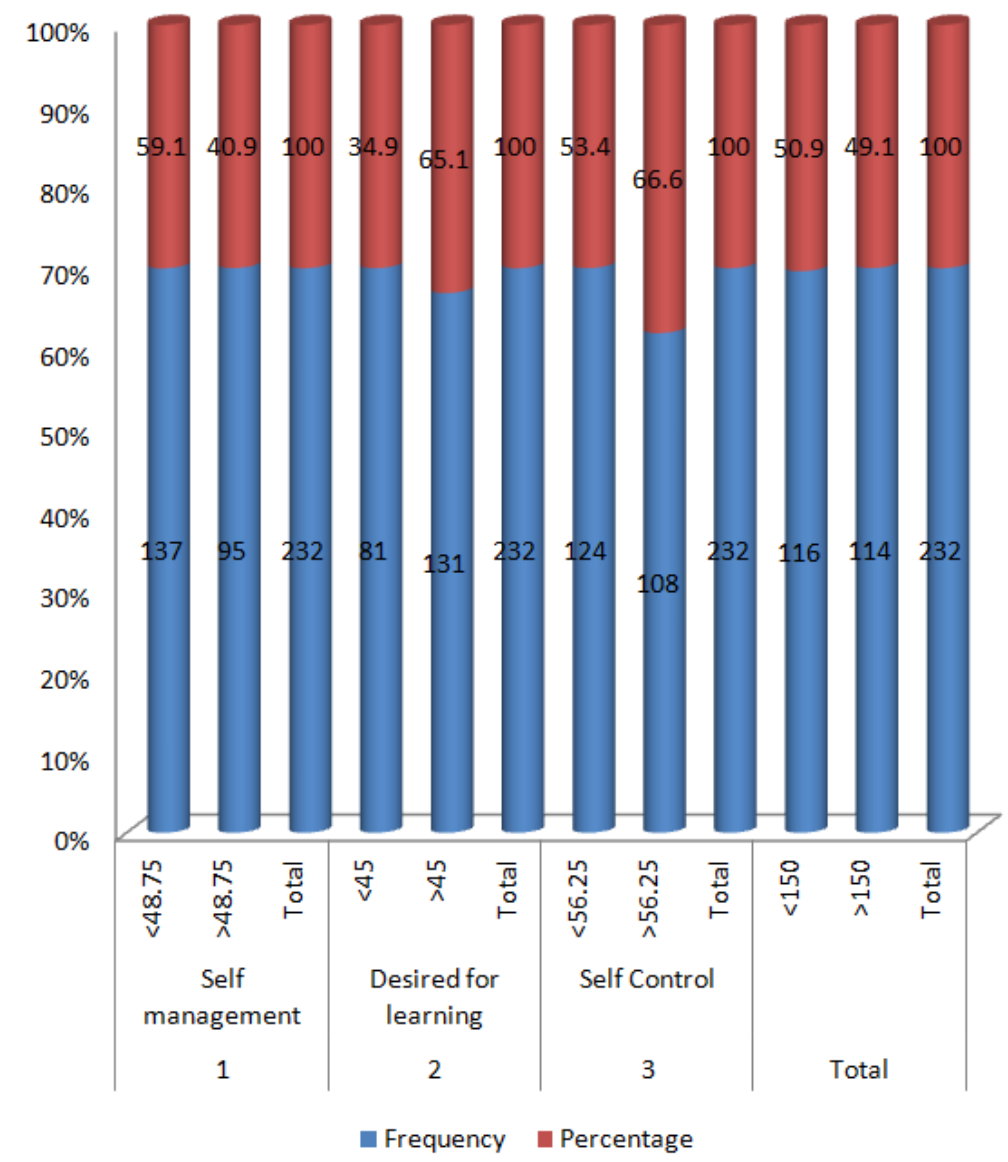

Figure 3. Number and percentages of the participants categorized according to classification of self-directed in learning, Tehran University of Medical Sciences, Tehran, Iran.

\section{Discussion}

The objective was to determine the self-Directed in
Learning among nursing students of TUMS. The present study revealed that the majority of undergraduate nursing students $(90.52 \%)$ have high level of SDLR(score $\geq 150$ ). This 
agree with ,Safavi et al(2010) who stated that majority of Jordanian and Iranian nursing students had high level of SDLR and perceived themselves as independent learner (14).In addition, the majority of students through SDL was a teaching method used alongside other methods, rather than a representation of beliefs about the adult self-learning (15). However, these results contradicted with the study of Lestari and Widjaja kusumah (2009) in Indonesia who indicates that $50 \%$ of the students had low to moderates scores for SDLR $(16,17,18)$. These scores are slightly higher than those reported from previous studies in other countries. The mean reason may be: this study indicated that understanding the different components of SDL which are carried out by undergraduate nursing students are very important as study finding students can be adjust their SDL to direct the needs of the students, due to the undergraduate nursing students' state to look at Self-control in self-directed learning during their learning process. Then this suggests that those who participated in this study had preferred one of the selfdirected learning but not all and the previous study may assess their participants only by total scores for SDL. In this study the mean scales of self-management, desired for learning, self-control, total SDL were 31.84, 31.83, 31.84, and 31.83 respectively. The mean total score of SDLR was 120.10. These mean scores are slightly higher than those reported from previous studies in other countries. The mean score of self-management, desire for learning and self-control were 51.3, 48.4 and 59.9 respectively among Saudi Arabia Under graduating nursing students, while the mean total score of SDLR was 159.6(19). However, when we compared with the previous study which done by El-Gilhany, had contradict. Because the mean score of desired for learning of SDL in previous study was lower than other SDL in the same study. The overall mean score of self-management, desired for learning, self-control and total SDLR was higher in previous study than this study. There was no statistical significant difference among all SDL. The SDLRS has been utilized to measure different adult students' SDL attitudes in numerous studies. Also, some scholars have examined the relationship of SDLRS with other instruments, such as crosscultural adaptability, LS, and creativity $(20,21,22,23)$. This indicated that the concept of SDL was not fully understood. The overall mean score of self-management, desired for learning, self-control and total SDLR was higher in previous study than this study. The main reason may be:-Sample size in this study was very small. Furthermore, SDLR is indicated as a set of feature that generally becomes more pronounced in previous study participants as they get knowledge.

\section{Conclusion}

This is the first study which conducted among undergraduate nursing students' SD in Learning in school of nursing and midwifery of TUMS. More research with larger groups is needed to generalize this result. Despite the lack of statistical significance in the relationship between selfdirected learning and their demographic characteristics in this study, there are several important findings that deserve future research. Researchers need to consider more effective means of assessing nursing students' SDL so that a higher response rate can be seen and the finding can also be achieved. The variables that were found to have statistical significance should be examined further. Self-directed learning is a method of teaching and learning increasingly used in nursing education, and the result of assessing SDLR is useful for educators to select appropriate teaching and learning methods for their students. The present study revealed that the overall SDLR of participants was at a high level. In order to implement this method at the Department of medical surgical nursing, it was important to assess SDL readiness of students. Data from this study can be used to further develop SDL in nursing students and to improve teaching and learning methods. Further research should follow the development of nursing students' SDL abilities over their academic years as well as their lifelong careers in Iran.

\section{Recommendations for Applications}

The recommendations for future research include:

- Educate all students who are attending universities, college and any higher educational level about the main purpose and importance of SDL.

- The study could be replicated in a greater number of nursing and midwifery schools at different Universities and institutions of higher education.

- Replicating the study with students in other educational disciplines might yield beneficial insight into classroom engagement as well.

- Persistence between gender groups was another serious issue in this finding that might also be an area of future research.

\section{Recommendations for Further Studies}

Conduct a study using Fisher's-SDLR with full permission in place of SDL which has been developed for the nursing profession. The main recommendation is to repetition of this study with a larger sample size. Conducting action research that would apply specific techniques to target diverse perspectives, communication with faculty and peers, asking questions in class, class discussions, and perceived difficulty of course work, and preparation for class is recommended.

\section{Acknowledgement}

We are grateful to all persons who provide technical help to this study and assisted in writing the manuscript. We are acknowledged international Campus Head for the material support.

\section{Author's Contributions}

AA, have made substantial contributions to beginning and design, collection of data, analysis and interpretation of data 
and in drafting the manuscripts and correcting the comment given by the advisors.SG, involved in revising the research paper and the manuscript critically for important intellectual context and approval of the final version to be published and participated in its design and coordination. He participated in the approval and funding process, participated in the design of the study participated in its design and coordination. NM, involved in revising the research paper and the manuscript critically for important intellectual context and approval of the final version to be published and participated in its design and coordination, and had greater contribution in reviewing the manuscript English and topography and helped to draft the manuscript.

Funding /Support

The study was supported by Tehran University of Medical Science International Campus for finalized this research But also Science Publication Group for publication waive.

\section{References}

[1] Tabatabaei, O(2012).The Effect of Self-Directed Learning on Critical Thinking of Iranian EFL Learners. . Journal of Educational and Social Research 2, 55-64.

[2] Fisher, M., J ., King, J( 2010). The Self-Directed Learning Readiness Scale for Nursing Education Revised:A confirmatory factor analysis. Nurse Educ.Today., 30, 44-48.

[3] Fisher, M., King, J., Togue, G(2001). Development of a selfdirected learning readiness. Nurse Education Today, 21, 516525 .

[4] Fisher, M., King, J., Togue, G( 2011). Development of a selfdirected learning readiness scale forenursing education. . Nurse Education Today, 21, 516-525.

[5] Chen, Y.-L., Hsu, L.-L.,Hsieh, S.-I(2012). Clinical Nurse Preceptor Teaching Competencies: Relationship to Locus of Control and Self-Directed Learning. Journal of Nursing Research, 20, 142.

[6] Dunn, R., Honigsfeeld, A., Doolan, L. S(2009). Impact of Learning Style Instructional Strategies or Students Achievement \& Attitudes;Perceptions of Educations of Educators Institutions. Education Journal, 82, 135-140.

[7] Dynan, L., Cate, T., Rhee, K (2008). The impact of learning structure on students' readiness for self-directed learning. . Journal of Education for Business, 84, 96-100.

[8] Deyo, Z., Hynn, D., Sturpe, D. , Kiser, K(2010). Readiness for self-directed learning and academic performance in an abilities laboratory course, . American Journal of Pharmaceutical Education, 75, 2.
[9] Fisher, M., King, J.,Togue, G(2011). Development of a selfdirected learning readiness scale forenursing education. . Nurse Education Today, 21, 516-525.

[10] Huang, M. H(2012). Factors Infulencing Self-Directed Learning Readiness Amongest Taiwanese Nursing Students. International Journal of Learning \&Development., 5, 1-9.

[11] Huange, M. H(2008). Factors influencing self-directed readiness amongst Taiwanese nursing students. Internet.

[12] Deyo, Z., Hynn, D., Sturpe, D. ,Kiser, K(2011). Readiness for self-directed learning and academic performance in an abilities laboratory course, . American Journal of Pharmaceutical Education, 76, 1.

[13] EL-Gilany, A. H. ,Abusaad, F. E(2012). Sef-directed learning readiness and learning styles among Saudi undergraduate nursing students. Nurse Edu-Today, $\mathrm{xxx}$, xxxxxx.doi.10.1016/j.nedt.2012.05.003.

[14] Safavi, M., Scooshtari, Z., S.H, MahamoodI, M. , Yarmohammadian, M. 2010. Self-directed learning readiness and learning styles among nursing students of Isfahan University of Medical Sciences. Iranina Journal of Medical Education, 10, 27-35.

[15] Miller, M. P.(2010). Are first year undergraduate students nurses prepared for self-directed learning? Nursing times.net.

[16] Lestari, E.,Widjajakusumah, D. (2009). Students' self -directed learning readiness,perception toward students -centered learning and predisposition towards students centered behavior. South East Asian Journal of Medical education, 3, 52-56.

[17] Israel Dunmade, Effectiveness of Term Projects in Helping Students to Connect Theory with Practice: an Evaluation of Students' Perspectives. Education Journal. Vol. 2, No. 1, 2013, pp. 1-6. doi: 10.11648/j.edu.20130201.11

[18] Benjamin K. Weeks, Megan Dalton. An Independent Learning Manual to Support Clinical Reasoning and Facilitate Reflection in Early Physiotherapy Student Placements: A Case Study. Education Journal. Vol. 2, No. 2, 2013, pp.58-63. doi: 10.11648/j.edu.20130202.15

[19] EL-Gilany, A. H. ,Abusaad, F. S(2013). Self-directed learning readiness and learning styles among Saudi undergraduate nursing students. Nurse Educ Today, 33, 1040-4 .Doi: 10.1016/j.nedt.2012.05.003.

[20] EL-Gilany, A.-H.,Abusaad, F. E. S(2012). Self-Directed Learning Readiness and Learning Styles Among Saudi Undergraduate Nursing Students. Nurse Edu.

[21] Merriam, S., Caffarella, R., Baumgartner, L. (eds.) (2007). Learning in adulthood: A comprehensive guide (4th ed.). 